\title{
Application of Total Quality Management in Developing Quality Assessment Model: The Case of Vietnamese Higher Education*
}

\author{
Quyen Le Hoang Thuy To NGUYEN ${ }^{1}$, Du Van NGUYEN ${ }^{2}$, Ngoc Nguyen Mong CHU $^{3}$, Van Hong TRAN ${ }^{4}$ \\ Received: August 01, 2020 Revised: October 11, 2020 Accepted: October 15, 2020
}

\begin{abstract}
The shift from elite education to mass education in Vietnam has met the demand for education for everybody as well as for quality human resource talent for an emerging nation. Under the resource constraint, understanding the quality dimensions of education and its priority level is important for effective and efficient policies. This study was carried out using both qualitative and quantitative methodologies to develop quality criteria and a ranking model. Two rounds of in-depth interviews were conducted with fifteen experts in the field, who were rectors, employers, and recruitment specialists to develop the quality framework applied in Vietnamese universities under total quality management (TQM), starting from the input of the senior secondary school leavers, through a teaching process to the output. The first round of interviews were unstructured questionnaires designed to explore the main factors in quality assessment model. The second round affirmed the experts' agreement on the assessment model. Then, fuzzy logic was applied to rank eight criteria in the quality assessment model into priority order: cost, teaching and administrative staff, leadership, curriculum, student-related factors, internationalization, admissions, and campus. The results are critical for identifying the necessary actions to enhance the education quality and to further research on the optimal quality model.
\end{abstract}

Keywords: Decision-Making, Education Management, Fuzzy Logic, Quality Assessment Model, Total Quality Management

JEL Classification Code: A22, C60, M10

\section{Introduction}

Education is considered the foundation for the development and growth of the individual and for the

\footnotetext{
*Acknowledgements:

This research is funded by the Ministry of Education and Training, Vietnam and Ho Chi Minh City Open University under the grant number B2020-MBS-01.

${ }^{1}$ First Author and Corresponding Author. Assistant Professor, Deputy Director, Office of Cooperation and Research Management, Ho Chi Minh City Open University, Vietnam [Postal Address: 97, Vo Van Tan Street, District 3, Ho Chi Minh City, 724000, Vietnam]

Email: quyen.nlhtt@ou.edu.vn

${ }^{2}$ Assistant Professor, School of Government, University of Economics Ho Chi Minh City, Vietnam. Email: dunv@ueh.edu.vn.

${ }^{3}$ Lecturer, School of Economic Mathematics and Statistics, University of Economics Ho Chi Minh City, Vietnam.

Email: chunguyenmongngoc@ueh.edu.vn

${ }^{4}$ Dean, Faculty of Accounting and Auditing, University of Finance -

Marketing, Ho Chi Minh city, Vietnam, hongvan@ufm.edu.vn

(C) Copyright: The Author(s)

This is an Open Access article distributed under the terms of the Creative Commons Attribution Non-Commercial License (https://creativecommons.org/licenses/by-nc/4.0/) which permits unrestricted non-commercial use, distribution, and reproduction in any medium, provided the unrestricted non-commercial
original is properly cited.
}

nation (Altuwaijri \& Kalyanaraman, 2020; MarquezRamos \& Mourelle, 2019). Traditional education, especially higher education, has been evaluated as very successful in knowledge transition to the community, meeting the essential needs of daily life, and professional careers of the learners (Duong et al., 2020). However, the social development trends of the 21 st century of democratization, globalization, and information communication technology have challenged the role of education (Fan \& Popkewitz, 2020; Pham et al., 2019). It needs to be transformed to introduce new ideas, which meet the needs in the contemporary context (Durkheim, 2013; Huckle et al., 1996).

"Democracy" stems from the Greek word, "people." Under democracy, the respect for citizenship is the priority. In education, democratization emphasizes equal access to education (Kanwar, 2012). This concept has been analyzed and enlarged by UNESCO, from equality of enrollment opportunities to educational resources access to educational outcomes and finally, to the free selection of educational options, so learners can meet their individual needs. Globalization was experienced in the economy and has spread around the world to fields including, politics, culture, and education (Levitt, 1993). Economic globalization has 
led to internationalization, popularization, competition, and cooperation in higher education. Technological innovation and change have been the driver of social progress. Artificial intelligence has impacted human competency education requirements towards emotion and attitudes in intensive jobs (Karacay, 2018). Four major trends have shaped education from the perspective of the two orientations: equity and four educational pillars. These are: (i) learning to know, (ii) learning to do, (iii) learning to live together, and iv) learning to be. Mass education, one of the features of higher education, is considered as an optimal means to meet these goals. However, developing a quality education is key (Lomas, 2002; Pham \& Starkey, 2016).

In recent decades, the higher education system in Vietnam has been profoundly changing in terms of scale, ownership, and training methods. Diversification has shifted elite education to mass education, with a rapid increase in the number of universities and enrolled students. Recent statistics show that 235 universities nationwide have a student population totaling over 1,707 thousand in 2017, compared to 125.5 thousand in 1991. Along with the rapid growth of universities, education quality has become a matter of social concern, taking priority in the Communist Party Resolution (Resolution No. 29-NQ/TW).

Quality is a multi-dimensional concept, which depends on context and stakeholders' views. The definition, furthermore, has changed and been modified over time to match the customers' needs and demands. Educational quality is no exception. Such definitions are, moreover, subject to the judgment of people's uncertainty and vagueness. Arslan Namli and Senkal (2018) have confirmed the reliability and flexibility of the fuzzy logic approach in evaluation and decision-making. This method addresses the accuracy of the input data, allowing the proper evaluation of education quality (Jaukovic Jocic et al., 2020; Kiet et al., 2020) Generally, this is an evaluation approach that has been embraced by the research community, given two outstanding advantages. Firstly, the assessment and ranking are objective and exclude emotional factors. Secondly, the score of each criterion is not a static number, but volatility, which promptly reflects the changes in human thinking. Therefore, this study aims to develop a model to assess the quality of Vietnamese higher education using the theoretical basis of fuzzy numbers as a remedy for ambiguous factors in the human judgment process.

\section{Literature Review}

Quality is the major focus because it is key to productivity and cost reduction (Nguyen et al., 2018). However, it is a multi-dimensional and contextual concept (Luong et al., 2018). Therefore, quality characteristics need to be detailed to be improved. For education, previous researchers have defined quality based on stakeholders' views. According to Welzant et al. (2015), education stakeholders can be divided into four groups: (i) providers (government agencies, funding institutions, and educational providers); (ii) service users (learners); (iii) outcome users (employers), and (iv) industry employees (professionals and administrators). At the market approach, the four groups can be further categorized into two subgroups: providers and customers. Though such a classification makes quality definition simpler, diverse human needs still exist.

Quality initiatives originated in industry, but they are widely applied in other sectors including education (Deming, 2018). The conventional concept of quality is excellence. A quality product is the one that has been perfected. Rare and expensive materials are associated with a quality product. However, quality and excellence are not interchangeable. Excellence only refers to one quality status, i.e., bad, good, excellent (Kiauta, 2012). In higher education, rankings have used this perspective with clarifications in management, research, teaching, and student performance (Brusoni et al., 2014). The same criteria cannot be applied universally because the absolute quality approach shall challenge mass and equity education. "Conformance to requirements" with the same level is another approach to the concept of quality (Crosby, 1979). It means that the product is evaluated as a quality one when it is within the range of certain specifications. This definition may be more valuable to higher education providers because quality can be improved by setting quality standards as guidelines to the path of achieving quality. Crosby's philosophy on quality is doing the right thing from the start. Thus, preventative action is emphasized in all processes, including thinking, planning, analyzing, and taking action. Any errors should have been foreseen and eliminated. This approach has value for education, given its special products, the learners. Having errors in education is not acceptable. Moreover, it is too costly. This view challenges the conventional approach between price and quality. With Crosby, when the quality increases, cost decreases. Low quality and cheap education are only excuses. Therefore, efficiency and effectiveness are included in this definition. However, the specifications, requirements, or standards are questionable.

Deming (2018) expanded on Crosby's view by focusing on customer satisfaction as a price to be paid when defining quality. This view was also shared by Juran and Gryna (1988) in his definition of quality as "fitness for use" for both the provider and customer. Thus, a purpose is specified and developed. For example, if higher education aims to provide a trained workforce to society, then quality is the degree to which undergraduates fit into the labor market. If the course's quality is evaluated, it will be interpreted in terms of the knowledge, skills, and attitudes achieved by learners after finishing. Fitness for use or purpose may 
including meeting the requirements of all the stakeholders. It also includes satisfying or overcoming pre-defined standards. It even mentions the requirements of the output perfection, effectiveness, and efficiency. Defining the purposes of education is key to its quality. Recent research has also confirmed the value of transformation in education (Leal Filho et al., 2018). Transformation is learners' growth in their "minds" and heart." Thus, the intellectual, emotional, and social development of learners at the center of quality. In short, the literature review on the definition of quality incorporates the following education quality dimensions: (i) achieving perfection, (ii) reaching certain thresholds, (iii) complying with requirements, (iv) realizing effectiveness and efficiency, (v) attaining fitness for purpose, (vi) having zero errors, and (vii) transformation. These dimensions reflect the evolution of the definition of quality. In the 1980s, quality referred to the perfection and excellence of elite education. When mentioning quality, the 1990s witnessed a shift in the orientation toward the customer. Entering the 21 st century, education quality had reached the four pillars (Carneiro, 2015). Quality education, thus, satisfies basic learning needs and helps to enrich the lives and experiences of learners. It gave leaners two benefits that enhanced their experience and empowered them.

Similar to quality, quality assurance is also a contextdependent concept with different approaches. It has been defined as a set of inside and outside arrangements, strategies, frameworks, and practices designed by the organization to attain, keep up, and improve quality (Berdahl \& Universitatum, 2011). The main purpose of quality assurance is to serve quality improvement and accountability. Accountability is the driver to gain education quality and is normally connected to public judgment about the fitness and the satisfaction level of the specified education goals (Smith \& Benavot, 2019; Yan, 2019). In education, accountability refers to the records of educational processes, consisting of input, processes, outputs, and goals that are used for institutional evaluation. Similar to accountability, improvement relates to a variety of perspectives. It aims to enhance future execution instead of focusing on past performance. Accountability and improvement seem to be mutual exclusively. The conflict between the two concepts has been discussed in the research, though they appear as a pair for the purpose of quality assurance. Quality assurance has several models: (i) quality control, (ii) quality assurance, (iii) quality assurance (internal value and external audit), and (iv) total quality management (TQM).

Quality control denotes the elimination of defective, unsatisfactory products (Arndt et al., 2019; Park \& Kim, 2019). This approach may create waste because it only the last step after the product has been created. On the other hand, the quality assurance model focuses on preventative action on error products (Dimou \& Kameas, 2016). This is a process that occurs before and during execution, from the very start to the end of the process. Thus, deficiencies can be avoided. To achieve high efficiency in this approach, transparency needs to be ensured, particularly in how things are organized and run. Moreover, an organization's mission and vision needs are well communicated to its employees. A difference between the internal and external audit of quality assurance is also suggested. Two typical styles of quality assurance were presented by the French and the British. While the French empower quality control over external agencies, the British pursues the autonomous community. In practice, the combination of the two styles is ideal. Internal quality review targets truth and knowledge. External quality audits provide a service to society. However, customer satisfaction is the top priority in the market. Therefore, total quality management (TQM), initiated by Deming then developed by Crosby, Ishikawa, and Juran has been considered the superior approach (Crawford \& Shutler, 1999; Mukhopadhyay, 2020). Not only input and process quality management but also quality culture are stressed in TQM so that customers can experience a continuous enhancement of quality.

Figure 1 shows a traditional diagram of the higher education process with the input of senior secondary school leavers. They undergo the teaching process with a final exam before entering the labor market or further education (graduate education). Those who fail on the final exam can resit. The consequence of this conventional approach is that, as Crosby noted, it increases costs. To properly cured the problem, TQM calls for the investigation of failure. Furthermore, such examination is being utilized as a demonstrative tool for continuous improvement because no examination failures (zero defects) do not mean the fitness for the labor market demand, especially in this technology-driven era.

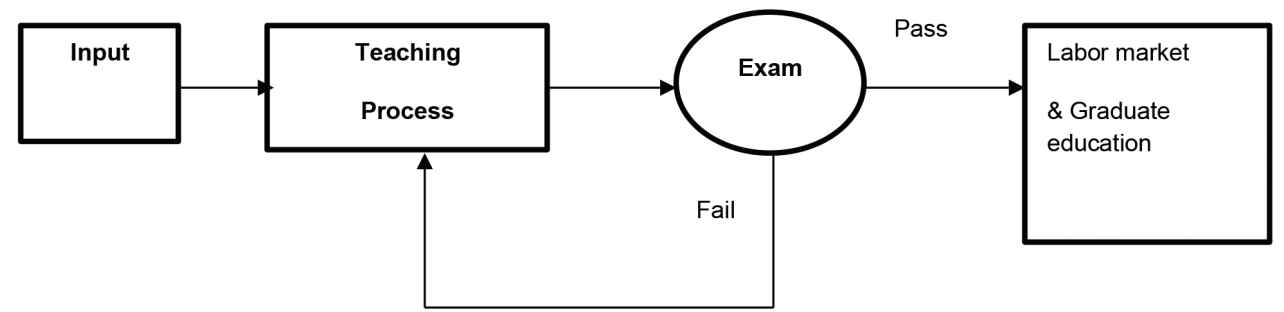

Figure 1: A mimic of the higher education process 
TQM is a framework for steady quality advancement that incorporates all workers from the top management to employees. The orientation toward the expectation of customers is always respected. Moreover, wastage or unnecessary costs are prevented and quality culture is nurtured. Tsinidou et al. (2010) recommended the application of quality function deployment (QFD), a branch of TQM for a quality assessment model that has learners as the starting point of the analysis. In the education process, exam failure is considered a milestone for remedial action. Inputs, teaching processes, and outputs as indicated in Figure 1 are the basis for quality evaluation. These factors were further deconstructed into subgroups of admission, students' performance, teacherrelated factors, institution's characteristics, and program (Grundey, 2008; Johnston, 1994). Entry requirements have been conventionally considered as the driver of quality based on the "garbage in, garbage out" prejudice. As a result, minimum intake requirements are regulated by the authorities. The recruitment of initial teacher education (ITE) in various countries is a typical illustration of such belief (Parker, 2018). Furthermore, related factors such as students' motivation, attitudes, proactivity also contribute to educational achievements (Harvey et al., 1993).

Sarrico and Alves (2016) asserted that teaching staff is among the key indicators of education quality. In TQM, quality commitment and understanding from employees within the organization are also crucial (Sahney, 2016). Therefore, the qualifications for teaching and administrative staff, or human resources, including research capacity, sincerity, professionalism, vocational consultation, extra services, timely response and feedback, industry cooperation are required (Zineldin et al., 2011). Vazzana et al. (2000) further demonstrated the interconnectivity of different factors in quality enhancement, in particular great teachers empowered by good teaching and learning processes together with an environment that is conducive to learning. Zineldin et al. (2011) developed an educational service quality model based on industry. It had two pillars: (i) hardware (facilities) and (ii) software (operation). Tsinidou et al. (2010) provided a set of criteria under these two pillars: campus location, facilities, library, material base, and educational program. The role of the curriculum in transforming learners and providing them with competencies to apply to the labor market has been empirically proven (Machalow et al., 2020; Stabback, 2016). Various components of the curriculum such as objective and learning outcomes, inputs, teaching activities, teaching content, teaching methodologies, evaluations, and assessment, teaching facilities have been shown to impact learners' competences (Amin et al., 2020). Leadership is the backbone of continuous quality improvement because it creates a quality culture in the institute through inspiration (Bouranta, 2020; Darling, 1992; Sfakianaki et al., 2018). It can start with the organization's vision and go through all the processes with those involved. It is the guideline for managing resources and addressing value and responsibility towards society with the focus on customers' demands. Effective leadership determining successful TQM is found in diversified research fields, including education (Levin, 1993). A summary of this chapter can be seen in the following six factors in a quality assessment model using TQM is below in Figure 2.

\section{Research Methodology}

As discussed above, there are many different views on quality. Therefore, to give a unified definition of higher education quality is difficult. In this study, the pragmatic approach was adopted Harvey et al., 1992). Quality is determined based on its dimensions (Lee et al., 2016). Some institutions may achieve a high score in one criterion but score low in another. The assessment depends on the expectations of the stakeholders.

Given this methodology, the following steps were carried out. Firstly, in-depth interviews were conducted with fifteen experts in the field (employers, rectors, recruitment specialists) to get some agreement on the higher education quality criteria in the Vietnamese context. The next step was developing the quality assessment model using the fuzzy logic approach to rank the criteria. Fuzzy logic is an artificial intelligence algorithm that uses mathematical logic to solve the problem of incorrect input values in order to reach exact conclusions (Nguyen et al., 2019; Phong et al., 2017). This is more practical, since people also find it difficult to express their decision clearly. We used the following CoA procedure for defuzzifying the fuzzy weights (Nguyen \& Nguyen, 2020):

$$
B_{w_{i}}=\left[\left(Z_{w_{i}}-X_{w_{i}}\right)+\left(Y_{w_{i}}-X_{w_{i}}\right)\right] / 3+X_{w_{i}}
$$

where $B_{w i}$ is the best non-fuzzy performance value.

\section{Results and Discussion}

In this research, the in-depth interviews with the fifteen experts were conducted to explore the dimensions of quality in Vietnamese higher education. Table 1 summarizes the description of the authors' survey data. There were more women in the sample than men, constituting $53.3 \%$ of the sample. This is a popular gender structure in human resources management in Vietnam. Most of the experts were from 40 to 49 years old. The majority of the sample held master's degrees. 
Quyen Le Hoang Thuy To NGUYEN, Du Van NGUYEN, Ngoc Nguyen Mong CHU, Van Hong TRAN/

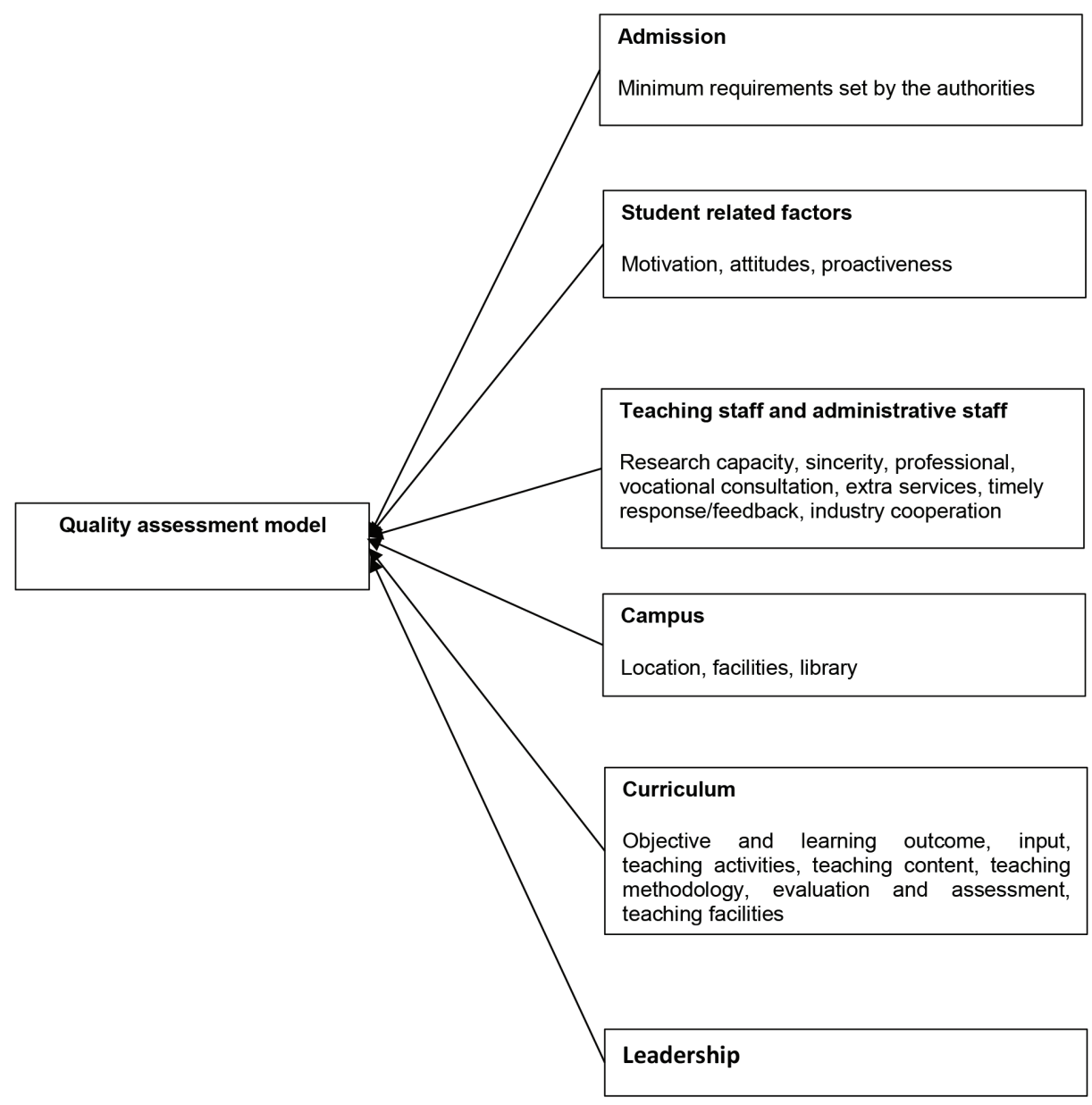

Figure 2: Six factors in a quality assessment model under the TQM approach

Table 1: Description of survey data

\begin{tabular}{|c|c|c|c|}
\hline \multicolumn{2}{|l|}{ Description } & Quantity & Percentage \\
\hline \multicolumn{4}{|c|}{ Experts' information } \\
\hline \multirow{2}{*}{ Gender } & Male & 7 & 46.7 \\
\hline & Female & 8 & 53.3 \\
\hline \multirow{4}{*}{ Age } & $<30$ & 2 & 13.3 \\
\hline & $30-39$ & 4 & 26.7 \\
\hline & $40-49$ & 6 & 40 \\
\hline & $>50$ & 3 & 20 \\
\hline \multirow{2}{*}{ Education level } & Master & 10 & 66.7 \\
\hline & $\mathrm{PhD}$ & 5 & 33.3 \\
\hline \multirow{3}{*}{ Experience } & Recruitment specialists & 5 & 33.3 \\
\hline & Employers & 5 & 33.3 \\
\hline & Rectors & 5 & 33.3 \\
\hline
\end{tabular}


Table 2: Research results

\begin{tabular}{|l|c|}
\hline Factors in the quality assessment model & Rank \\
\hline Cost & 1 \\
\hline Teaching and administrative staff & 2 \\
\hline Leadership & 3 \\
\hline Curriculum & 4 \\
\hline Students-related factors & 5 \\
\hline Internationalization & 6 \\
\hline Admission & 7 \\
\hline Campus & 8 \\
\hline
\end{tabular}

The discussion with experts led to the addition of "cost" and "internationalization" to the criteria for this higher education assessment model. Higher education in Vietnam has traditionally been subsidized by the government. When moving to an autonomous mechanism, the correct and sufficient cost calculation was the condition for educational development. This was also the basis for calculating whether the government had an adequate investment in public schools. Also, education providers can offer the right tuition. Proper policies to ensure equity in accessing education opportunities (scholarships and student financing schemes) can be made. All contribute to the quality of higher education. The experts also agreed that the contemporary situation had boosted the internalization of education. Education in general, especially higher education has become borderless. The opportunities for those who want to study are available with many alternatives, either locally or abroad; or face to face or virtual. In this competition, the academic program of the local university needs to orient to international standards for articulating. The design of the standard curriculum with the content accessible to the advanced countries level is not an easy mission if no world integrating activities have been done. The qualitative research resulted in an assessment model with eight criteria. The criteria ranking was further calculated with fuzzy approach. The result in Table 2 confirms the role of cost, which is ranked first in the model.

The research results show that cost is always the most decisive factor when discussing education quality in Vietnam with its growth in the number of autonomous universities. This is also a base for tuition fees, which is viewed as "price" for quality. The second factor is the human resource, which directly influences the training process in the university. The lecture quality depends on teaching staff qualifications. The program may be good, but it will fail without proper teachers. A good script goes along with good actors and actresses and should be kept in mind when developing the program. Moreover, lecturers play an important role in learner motivation, which leads to a self-study process as well as their learning capacity. Students often do not understand how to self-study because teachers do not know how to inspire or teach students. The human factor, not only refers to the teaching team, but also the administrative team. A good team must be available to support program preparation, schedule, teaching facilities, and equipment, etc. Therefore, quality teaching and administrative staffs are key for training quality. Leadership is third in the model. Good leadership positively influences employees and systems to reach successful results. An effective leader creates and maintains the internal environment of the school to engage people to achieve their goals. Besides, the vision together with short term and long term goals, appropriate methods to achieve the goals are also identified by the leader.

The curriculum is ranked fourth; it is vital to achieving student competency. In a study on the quality of Egyptian private universities, Mostafa (2006) discovered that the role of the curriculum was the backbone of quality. The curriculum ranked lower for Vietnamese higher education because it can be adapted to the world through internationalization, which is the fifth factor for improving training quality. Cooperating with foreign partners in training improves local training quality. It is used by local universities to make comparisons and undertake self-evaluation. If an institution looks outside itself, it will be more motivated to improve and grow. The concept of an "international standard" is general and without specifications. However, looking at universities around the world and how they function drives local universities to understand more about who they are and where they are stand. This is the goal of "internationalization." At present, the Vietnamese higher education institutions do not seem to understand the concept of "international universities," "international class," and "international standards." Further, introducing a poor concept can lead to inconsistencies and inaccuracies and will be very dangerous. Thus, at the beginning, introducing international education integration into higher education should begin simply with joint training and articulation.

The seventh criterion relates to students. Their motivation and positive attitudes can lead them to be interested and thorough when studying, which determines their performance and competences. Self-studying is a learning mode that maximizes the learners' self-awareness in research and knowledge exploration. In addition, a pattern of life-long learning is formed. Admission and campus are ranked as less important to the model though they still have a role. In Vietnam, senior secondary-school-leavers need to meet a minimum requirement set by the Ministry of Education and Training to be admitted into a university. In a technology-driven society, all campus facilities must be modernized. Teachers can no longer teach only with white chalk and a blackboard. A good training program must have the appropriate facilities, equipment, infrastructure, lecture 
hall, etc. These are also important conditions to help improve the quality of higher education.

\section{Conclusions}

This research emphasized the role of cost in sustaining education quality and contributing to the expansion of autonomous universities that Vietnam has been undertaking since 2012. Using both qualitative and quantitative methods, contextual higher education quality criteria have been identified and ranked, providing the foundation for further research in the field to develop an optimal quality model. The research results show that the eight main criteria in the quality assessment model in Vietnam are: (1) cost, (2) teaching and administrative staff, (3) leadership, (4) curriculum, (5) students-related factors, (6) internationalization, (7) admission, and (8) campus. Moreover, these eight criteria and their priority will contribute to the quality of Vietnamese universities under their resource constraints.

\section{References}

Altuwaijri, B. M., \& Kalyanaraman, L. (2020). CEO educationperformance relationship: Evidence from Saudi Arabia. Journal of Asian Finance, Economics and Business, 7(8), 259268. https://doi.org/10.13106/jafeb.2020.vol7.no8.259

Amin, N. A. N., Almunawar, M. N., Hasnan, A. S., \& Besar, N. N. (2020). The Utilization of Web 2.0 for Knowledge Sharing: The Case of Tertiary Education in Brunei Darussalam. In: Handbook of Research on Managerial Practices and Disruptive Innovation in Asia (pp. 1-25). IGI Global.

Arndt, T., Kumar, M., Lanza, G., \& Tiwari, M. K. (2019). Integrated approach for optimizing quality control in international manufacturing networks. Production Planning and Control, 30(2-3), 225-238. https://doi.org/10.1080/09537287.2018.153 4271

Arslan Namli, N., \& Senkal, O. (2018). Using the Fuzzy Logic in Assessing the Programming Performance of Students. International Journal of Assessment Tools in Education, 5(4), 701-712.

Berdahl, R., \& Universitatum, O. O. T. M. C. (2011). Contemporary threats and opportunities: academic freedom and institutional autonomy within the context of accreditation, quality assurance and rankings; proceedings of the conference of the Magna Charta Observatory, 15-16 September 2011. Bononia University Press.

Bouranta, N. (2020). Does transformational leadership influence TQM practices? A comparison analysis between manufacturing and service firms. TQM Journal. https://doi.org/10.1108/TQM12-2019-0296

Brusoni, M., Damian, R., Sauri, J. G., Jackson, S., Kömürcügil, H., Malmedy, M., \& Pol, P. (2014). The concept of excellence in higher education. Occasional Papers, 20.
Carneiro, R. (2015). Learning: The treasure within-Prospects for education in the 21 st century. European Journal of Education, 50(1), 101-112.

Crawford, L. E. D., \& Shutler, P. (1999). Total quality management in education: Problems and issues for the classroom teacher. International Journal of Educational Management, 13(2), 6773. https://doi.org/10.1108/09513549910261122

Crosby, P. B. (1979). Quality is free: The art of making quality certain (Vol. 94). New York, NY: McGraw-Hill.

Darling, J. R. (1992). Total Quality Management: The Key Role of Leadership Strategies. Leadership \& Organization Development Journal, 13(4), 3-7. https://doi. org/10.1108/01437739210013388

Deming, W. E. (2018). Out of the Crisis. Cambridge, MA: MIT press.

Dimou, H., \& Kameas, A. (2016). Quality assurance model for digital adult education materials. Quality Assurance in Education, 24(4), 562-585. https://doi.org/10.1108/QAE-032015-0008

Duong, M. T. H., Nguyen, D. V., \& Nguyen, P. T. (2020). Using Fuzzy Approach to Model Skill Shortage in Vietnam's Labor Market in the Context of Industry 4.0. Engineering, Technology \& Applied Science Research, 10(3), 5864-5868.

Durkheim, E. (2013). The evolution of educational thought: Lectures on the formation and development of secondary education in France (Vol. 2). London, UK: Routledge.

Fan, G., \& Popkewitz, T. S. (2020). Handbook of Education Policy Studies: Values, Governance, Globalization, and Methodology (Vol. 1). Springer Nature.

Grundey, D. (2008). TQM in university studies: Quality assessment and quality assurance in a Lithuanian University. Transformations in Business and Economics, 7(2 SUPPL. B), 216-235.

Harvey, L., Burrows, A., \& Green, D. (1992). Criteria of quality: Summary. Quality in Higher Education Project Birmingham.

Harvey, L., Green, D., \& Burrows, A. (1993). Assessing Quality in Higher Education: A transbinary research project. Assessment \& Evaluation in Higher Education, 18(2), 143-148. https://doi. org/10.1080/0260293930180206

Huckle, J., Sterling, S., \& Sterling, S. R. (1996). Education for sustainability. London, UK: Earthscan.

Jaukovic Jocic, K., Jocic, G., Karabasevic, D., Popovic, G., Stanujkic, D., Zavadskas, E. K., \& Thanh Nguyen, P. (2020). A novel integrated piprecia-interval-valued triangular fuzzy aras model: E-learning course selection. Symmetry, 12(6), 928. https://doi.org/10.3390/sym12060928

Johnston, R. J. (1994). Quality assessment of teaching: Inputs, processes and outputs. Journal of Geography in Higher Education, 18(2), 184-193. https://doi.org/10.1080/ 03098269408709256

Juran, J. M., \& Gryna, F. M. (1988). Juran's quality control handbook (Vol. 4): New York, NY: McGraw-Hill. 
Kanwar, A. (2012). Democratising higher education through open education resources: From commitment to action. Vancouver, Canada: Commonwealth of Learning.

Karacay, G. (2018). Talent development for Industry 4.0. In: Industry 4.0: Managing the digital transformation (pp. 123136). Springer.

Kiauta, M. (2012). Idea of quality versus idea of excellence. Quality Innovation Prosperity, 16(2), 103-114. doi:10.12776/ qip.v16i2.74

Tong, K. T., Nguyen, Q. L. H. T. T., Nguyen, T. T. M., Nguyen, P. T., \& Vu, N. B. (2020). Applying the Fuzzy DecisionMaking Method for Program Evaluation and Management Policy of Vietnamese Higher Education. Journal of Asian Finance, Economics and Business, 7(9), 719-726. https://doi. org/10.13106/jafeb.2020.vol7.no9.719

Leal Filho, W., Raath, S., Lazzarini, B., Vargas, V. R., de Souza, L., Anholon, R., \& Orlovic, V. L. (2018). The role of transformation in learning and education for sustainability. Journal of Cleaner Production, 199, 286-295. https://doi.org/10.1016/j. jclepro.2018.07.017

Lee, M. J., Huh, C., \& Jones, M. F. (2016). Investigating quality dimensions of hospitality higher education: From students' perspective. Journal of Hospitality \& Tourism Education, 28(2), 95-106.

Levin, L. S. (1993). The role of leadership in total quality management. Engineering Management Journal, 5(1), 17-18.

Levitt, T. (1993). The globalization of markets. Readings in International Business: A Decision Approach, 249.

Lomas, L. (2002). Does the development of mass education necessarily mean the end of quality? Quality in Higher Education, 8(1), 71-79.

Luong, D.-L., Tran, D.-H., \& Nguyen, P. T. (2018). Optimizing multi-mode time-cost-quality trade-off of construction project using opposition multiple objective difference evolution. International Journal of Construction Management, 01-13.

Machalow, R., Remillard, J. T., Van Steenbrugge, H., \& Kim, O.-K. (2020). How Curriculum Materials Support Teachers' Noticing of Student Thinking. In: Elementary Mathematics Curriculum Materials (pp. 195-226). Springer.

Marquez-Ramos, L., \& Mourelle, E. (2019). Education and economic growth: an empirical analysis of nonlinearities. Applied Economic Analysis, 27(79), 21-45.

Mostafa, M. M. (2006). A comparison of SERVQUAL and IP analysis: Measuring and improving service quality in Egyptian private universities. Journal of Marketing for Higher Education, 16(2), 83-104.

Mukhopadhyay, M. (2020). Total quality management in education. Thousand Oaks, CA: Sage Publications.

Nguyen, P. T., \& Nguyen, Q. L. H. T. T. (2020). Critical Factors Affecting Construction Price Index: An Integrated Fuzzy
Logic and Analytical Hierarchy Process. Journal of Asian Finance, Economics and Business, 7(8), 197-204. https://doi. org/10.13106/jafeb.2020.vol7.no8.197

Nguyen, P. T., Nguyen, T. A., Nguyen, Q., \& Huynh, V. D. B. (2018). Application of SWOT for construction company quality management using building information modelling. Journal of Mechanics of Continua and Mathematical Sciences, 13(5), 25-33. https://doi.org/10.26782/jmcms.2018.12.00003

Nguyen, P. T., Vu, N. B., Nguyen, L. V., Le, L. P., \& Vo, K. D. (2019). The Application of Fuzzy Analytic Hierarchy Process $(F-A H P)$ in Engineering Project Management. Paper presented at the 2018 IEEE 5th International Conference on Engineering Technologies and Applied Sciences, ICETAS 2018.

Park, J., \& Kim, M. (2019). Analysis of requirements using Quality Function Deployment (QFD) in virtual reality(VR). Journal of Distribution Science, 17(2), 101-107. https://doi.org/10.15722/ jds.17.02.201902.101

Parker, S. (2018). Literature review on teacher education entry requirements. School of Education, University of Glasgow.

Pham, H. C., Dao, N.-N., Cho, S., Nguyen, P. T., \& Pham-Hang, A.-T. (2019). Construction Hazard Investigation Leveraging Object Anatomization on an Augmented Photoreality Platform. Applied Sciences, 9(21), 4477.

Pham, H. T., \& Starkey, L. (2016). Perceptions of higher education quality at three universities in Vietnam. Quality Assurance in Education, 24(3), 369-394.

Phong, N. T., Phuc, V. N., \& Quyen, T. T. H. L. N. (2017). Application of Fuzzy Analytic Network Process and TOPSIS Method for Material Supplier Selection. Key Engineering Materials, 728, 411-415.

Sahney, S. (2016). Use of multiple methodologies for developing a customer-oriented model of total quality management in higher education. International Journal of Educational Management, 30(3), 326-353.

Sarrico, C. S., \& Alves, A. A. (2016). Academic staff quality in higher education: an empirical analysis of Portuguese public administration education. Higher Education, 71(2), 143-162. https://doi.org/10.1007/s10734-015-9893-7

Sfakianaki, E., Matsiori, A., Giannias, D. A., \& Sevdali, I. (2018). Educational leadership and total quality management: Investigating teacher leadership styles. International Journal of Management in Education, 12(4), 375-392. https://doi. org/10.1504/IJMIE.2018.095165

Smith, W. C., \& Benavot, A. (2019). Improving accountability in education: the importance of structured democratic voice. Asia Pacific Education Review, 20(2), 193-205.

Stabback, P. (2016). What Makes a Quality Curriculum? InProgress Reflection No. 2 on "Current and Critical Issues in Curriculum and Learning". UNESCO International Bureau of Education. 
Tsinidou, M., Gerogiannis, V., \& Fitsilis, P. (2010). Evaluation of the factors that determine quality in higher education: an empirical study. Quality Assurance in Education, 18(3), 227244. https://doi.org/10.1108/09684881011058669

Vazzana, G., Elfrink, J., \& Bachmann, D. P. (2000). A Longitudinal Study of Total Quality Management Processes in Business Colleges. Journal of Education for Business, 76(2), 69-74. https://doi.org/10.1080/08832320009599955

Welzant, H., Schindler, L., Puls-Elvidge, S., \& Crawford, L. (2015). Definitions of quality in higher education: A synthesis of the literature. Higher Learning Research Communications, $5(3), 2$.

Yan, Y. (2019). Making accountability work in basic education: reforms, challenges and the role of the government. Policy Design and Practice, 2(1), 90-102.

Zineldin, M., Akdag, H. C., \& Vasicheva, V. (2011). Assessing quality in higher education: New criteria for evaluating students' satisfaction. Quality in Higher Education, 17(2), 231-243. https://doi.org/10.1080/13538322.2011.582796 